\title{
Cultural landscape planning: the Mexicali Valley, Mexico
}

\author{
R. I. Rojas-Caldelas ${ }^{1}$, C. A. Pena-Salmon ${ }^{1} \&$ J. Ley-Garcia ${ }^{2}$ \\ ${ }^{I}$ Faculty of Architecture and Design, \\ Autonomous University of Baja California, Mexicali, México \\ ${ }^{2}$ Institute of Research in Social Sciences, \\ Autonomous University of Baja California, Mexicali, México
}

\begin{abstract}
Initiating around the eighties, the academic training of landscape architects in Mexico is quite recent compared with the tradition in Europe and the U.S. Also new, is the development of landscape research conducted mainly by geographers, urban planners and other professionals trained in natural sciences, whose work is primarily oriented to land use management for urban development and conservation of natural resources or cultural heritage purposes. However, the issue of the cultural landscape in Mexico has been little explored and lacks any integrated and multidisciplinary methodology to bring together social, cultural and natural processes for study. Therefore, this work focuses on the presentation of an appropriate methodology to address the issue of the evolving cultural landscape of the Valley of Mexicali. This work has been developed into three stages: characterization, multiple assessment of landscape and integration of strategies for their management. Thus progress will be presented for the characterization of physical units, landscape components through pictures, visual and spatial patterns of landscape that structure the region and its settlements. As a partial result it was found that multi-valued zones visually and spatially exist in the Mexicali Valley, as well as activities that give character and differentiate it from other agricultural areas of Baja California.

Keywords: cultural landscape, landscape assessment methodologies, visual and spatial assessment, sustainable landscape planning.
\end{abstract}




\section{Introduction}

The study of landscape has evolved over time, moving from disciplinary approaches to multidisciplinary ones. Hence the study of this field has been enriched from numerous disciplines such as geography, ecology, architecture, urbanism, history and psychology, where each one of them has focused on the treatment of different aspects of the landscape.

In the case of disciplinary approaches, geography is a major one that has given several contributions: physical geography stands out in the role played by climate, geology, geomorphology, hydrology, soils, vegetation and wildlife modeling the landscape through different processes [1]. Geography has also given support for landscape evaluation forms, by first describing its features and then classifying and evaluating them based on multiple land use for production, settlements and conservation [2]. Human geography focuses on the study of the territory as a social construction designed to characterize and explain the patterns of territorial distribution of population along time [3].

From the point of view of landscape ecology, this approach takes into account the systemic nature and hierarchy of space, emphasizing the flows between their elements with others in a space, rather than focusing on internal flows to each item, knowledge that according to Matteucci [4] contributes to the design of natural reserves and their ties to the urban environment.

Landscape from an architectural and urban historical perspective, has dealt with the transformation of the natural environment through its buildings, the creation and development of human settlements and productive activities, where visual, and spatial aesthetic appreciation of urban landscape are weighted, but also for the evaluation of natural landscapes for conservation qualified for their beauty or unique features.

Approaches known as holistic are integrated and multidisciplinary proposals that have been built since the early 1970s have gone from an eco-development framework to a sustainable one, which have set the basis for changing the view towards addressing environmental social and economic problems, resulting from urban, regional, rural and natural protected areas planning and management. In this way disciplinary knowledge that was running parallel in the past, nowadays has found convergence in a broad sense in planning and management of the landscape.

The European Landscape Convention provides a broad framework to study the landscape and also a way to meet the challenge of sustainable development [5]. Therefore landscape places a key piece bridging the gap between people and their cultures and nature and its systems, perspective shared in the field of urban, regional and rural development planning [6].

Landscape is a result of the dynamic interaction between man and nature throughout time, where the study of history becomes crucial and so the management of landscape in different territorial scales. Another relevant issue is the inclusion of local actors into decision-making processes in the design, planning and management of programmes and projects, which altogether contribute to achieve sustainable development [6]. 
Landscape is an exercise that involves the coordinated multidisciplinary work that requires a large number of quantitative and qualitative tools to support different types of research [7]. This creates the foundation for the integration of a balanced approach that simultaneously pursues several objectives that integrate the expertise and knowledge of people [8]. Table 1 summarizes changes that have experienced the concept of landscape, from a disciplinary to multidisciplinary outlook.

Table 1: Approaches to landscape assessment.

\begin{tabular}{|c|c|}
\hline $1970-1990$ & $1990-2011$ \\
\hline Disciplinary knowledge & Multidisciplinary knowledge \\
\hline Skilled knowledge & People knowledge \\
\hline $\begin{array}{c}\text { Importance of landscape under protection } \\
\text { categories }\end{array}$ & $\begin{array}{l}\text { Importance of landscape as a daily experience } \\
\text { for conservation and development purposes }\end{array}$ \\
\hline Use of quantitative tools & Use qualitative tools \\
\hline Expert decision making & Shared decision with local actors \\
\hline Landscape evaluation & Multiple assessment of landscape \\
\hline Landscape as a static object along time & Landscape as a dynamic object along time \\
\hline $\begin{array}{c}\text { Research oriented to the development of tools, } \\
\text { measurement, description, evaluation and } \\
\text { simulation }\end{array}$ & $\begin{array}{l}\text { Research oriented to development of their own } \\
\text { framework and tools for integration }\end{array}$ \\
\hline Independent sectoral policies & $\begin{array}{l}\text { Comprehensive policies converging towards a } \\
\text { common goal }\end{array}$ \\
\hline $\begin{array}{c}\text { The concept of landscape is fragmented in the } \\
\text { legislation }\end{array}$ & $\begin{array}{c}\text { The concept of landscape is integrated in the } \\
\text { legislation }\end{array}$ \\
\hline Landscape as an isolated element & $\begin{array}{c}\text { Landscape that interacts with other landscapes } \\
\text { on different scales }\end{array}$ \\
\hline Land use planning & $\begin{array}{l}\text { Integration of economic, social, environmental, } \\
\text { cultural and spatial planning }\end{array}$ \\
\hline
\end{tabular}

Source: Elaborated by the authors

\section{Approaches that deals with the assessment of cultural landscape}

Literature review on cultural landscape deals with at least four general proposals that pursue different objectives and goals: the first is based on sustainability and the identification of landscape attributes without qualifying purposes [9]. The second is focused on cases where there is a need to approach the problem from a historical perspective to plan and manage the cultural and architectural heritage [10]. The third highlights the aspects of planning and ecological management of the landscape at regional and urban development scales [8]. The fourth is dedicated to the treatment of the cultural aspects of the landscape [11]. This last proposal takes into consideration natural and human processes, the role of 
history and landscape values for people, regardless of the value it has to put it in some category of protection.

Such approaches are the basis for the proposed methodology to study the Mexicali Valley landscape as a matter of historical rescue under the category of an evolving heritage given its recent history of a little over a hundred years. This region has its own ecological and productive character within a desert area and the Mexican-American cultural interaction that keeps its people as a valley located in the border between Mexico and the United States.

The general framework is sustainable development applied to the study of landscape considering the assessment of its multiple dimensions and in a specific way to landscape character. This methodological proposal facilitates adaptations to meet the particular conditions under study, history, geography, territory and landscape management regulations.

\section{Methodology Mexicali Valley cultural landscape}

The proposal for the study of the Mexicali Valley as a cultural landscape originated from the division of landscape into two main processes that have shaped its present features and future dynamics: those of natural conditions and, those resulting from human activity. The Valley of Mexicali today is the product of the domestication of the Colorado River Delta by pioneers of the early twentieth century. They changed this arid region of the Sonora Desert into an oasis. It has also been the arena between two cultures, Mexican and American, fighting to generate their own culture on the Mexican side of the border. Both conditions pose a challenge for this region to be studied under contemporary integrative approaches, allowing an evaluation of the landscape from its many dimensions to finally be able to influence its planning and a sustainable management of its natural heritage and cultural resources.

Each of these processes talks about the dynamics and assessments the landscape has had in different moments of its history, history that is still in construction day by day. Regarding the environmental conditions present in this region such as climate, geology, hydrology and vegetation, they initially facilitated the definition of physical and visual units of landscape for the purpose of inventory and characterization; as well as, the landscape subdivision proposal in accordance with its main land usage and urban characteristics of its human settlement that allow their differentiation.

Concerning the processes of landscape transformation by humans, several periods of time in which changes that responded to internal and external factors were identified. These were related to demographic, economic, technological, social movements and changes in the norms and organization of institutions.

On the other hand, cultural aspects of qualitative assessment of the landscape by its population were also considered. Some of the aspects such as aesthetic, visual and spatial stand out from the rest and contribute by giving this landscape an identity different from others in the same context. 


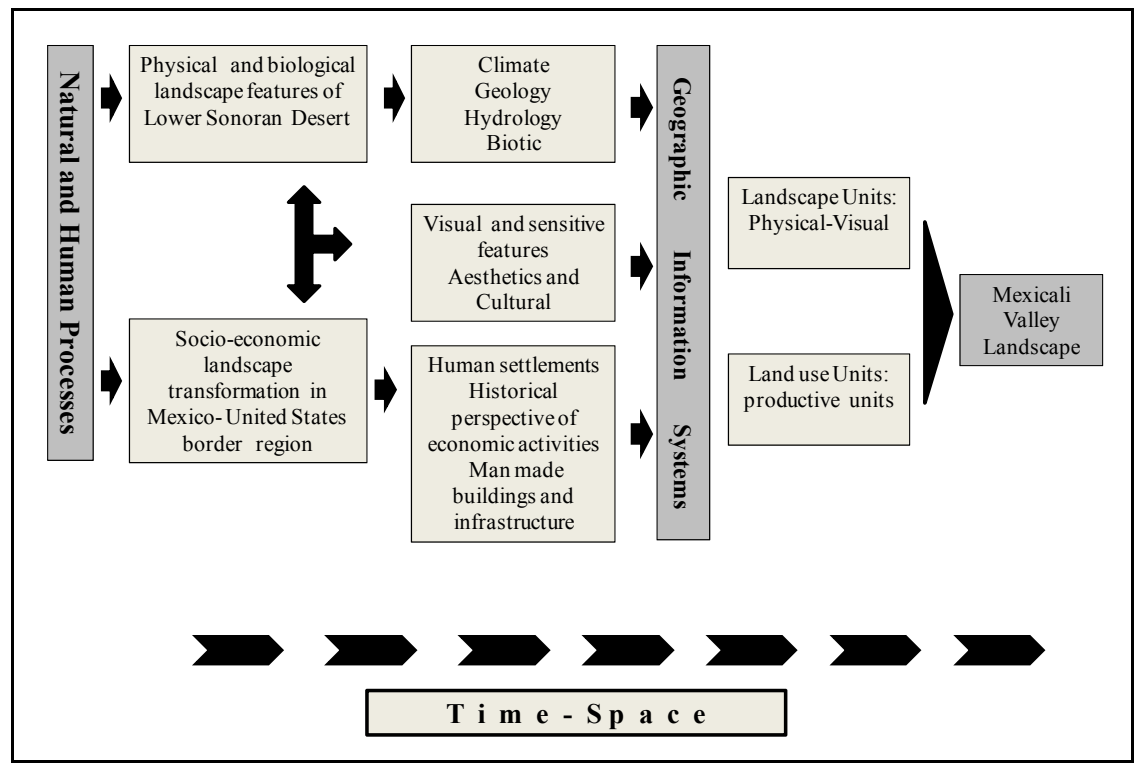

Source: Elaborated by the authors.

Figure 1: Methodology of multiple cultural landscape values: Mexicali Valley.

Qualitative and quantitative tools were used in each of the sections of the methodology. The greater challenges faced on this stage are integration and crossing of variables in order to be able to interpret the landscape. This phase will take place partially through the use of geographic information systems.

The methodology of this research focuses on: the inventory and description of the units of the landscape, the subdivision of the territory by land usage; the structure of the space through photographs of the main routes of public transportation; the characteristics of the elements of the landscape from the identified landscape units; and the characterization of human settlements through their shapes. The phase of assessment of preferences will take place at another point of the research.

\section{The Mexicali Valley landscape}

\subsection{Physical units}

The Mexicali Valley represents the physiographic sub province known as the Lower Delta of the Colorado River; it belongs to the physiographic province of the Sonoran Plains, located in the U.S. Mexico border. One of the vertexes of the delta is set in Yuma, Arizona, USA, and Algodones, Baja California, Mexico. The second is located south of El Mayor Hill and, the third is at the foot of the Centinela Hill (figure 2). 


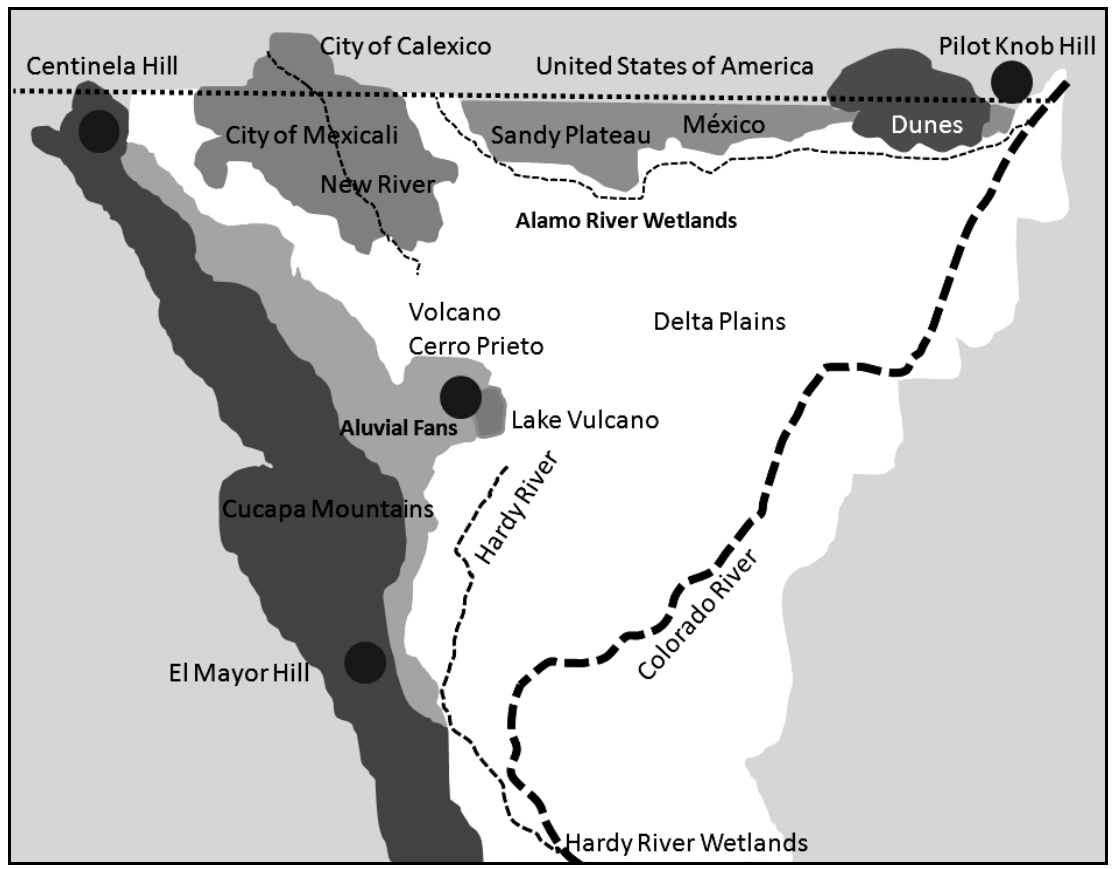

Source: Elaborated by the authors.

Figure 2: $\quad$ Physical and visual landscape units.

This wide area is $6711.85 \mathrm{~km} 2$, was divided into 11 subunits according to homogeneous geological, relief, soils and vegetation traits of landscape:

Delta Plain. The Mexicali Valley is located in a Colorado River delta plain, with a total surface of 207,000 hectares, the relief is slightly flat and a large cultivated surface.

The Colorado River. The water comes from the Rocky Mountains in the United States and ends in the Gulf of Cortes, Mexico, passing through the flooded plain of the delta, where it has left many marks engraved on the surface through its many twists and turns, which has brought a particular character of the land allotment and reddish color to their soils.

Mesa Arenosa de Andrade (Sandy Plateau of Andrade). This unit is a gently sloping plateau, consisting of sandy soils of medium texture and light color thick and scatter arid shrubs.

Morros. Small sand banks 2 to 3 meters high; reddish, sloppy surface; its distribution is associated with the formation of ancient river meanders and also has scatter vegetation. 
Algodones Dunes. Dunes are prominent in the landscape; they are 50 to 70 meters high; undulating surfaces and fine sand soils without vegetation.

Pilot Knob Hill. Although this hill is in the U.S. it is a landmark that identifies the town of Algodones, it is 227 meters high; composed of volcanic rock, dark colored, irregular profile, steep slopes, rocky and apparently no vegetation.

Wetlands of the Alamo River and Hardy River. The first one is linked to the old Alamo River running along the bottom of the Mesa Arenosa de Andrade, highlighted by the presence of low height masses of vegetation. In the second case, Hardy River Wetlands are located south of the valley at the end of mouth of the delta toward the Sea of Cortez.

Centinela Hill. It is a granite hill, apparently without vegetation, triangular in shape and 500 meters high; those attributes distinguish it as an identity symbol of the municipality of Mexicali.

New River. This body of water is now fed by wastewater from agricultural fields north of the valley; gray water from domestic sewage and treated wastewater. The river has two small lakes: Xochimilco and Mexico surrounded by residential developments located along the river.

Cucapah Mountains slope. It is a sloping surface that was formed by alluvial fans coming down the mountains. It is made up of sandy soil and desert vegetation.

Volcano Lake. At the foot of Cerro Prieto hill the body of water known as Volcano Lake is found. In the past it was a thermal spring, but nowadays it is an artificial lake fed by waste water derived from processes of energy generation from geothermal sources located in this region.

\subsection{Subdivision of units by land uses}

Agriculture. With regard to agriculture, the landscape is seasonal and depends on the cycles of spring-summer or autumn and winter with the dominance of certain crops, depending on the area. In general, large areas of grasslands are found where grasses such as rye grass grow. Also, grains such as wheat, sorghum, maize, cotton and vegetables such as asparagus, tomatoes, celery, onions, lettuce, cabbage and small areas with perennial crops mainly citrus, dates, cactus, and grapes.

Agro-industries. They are set in the valley near settlements and they represent the infrastructure for grain, pasture, wheat and cotton collection, storage and transportation; for slaughterhouses, packing plants, warehouses, nurseries and greenhouses. Other kinds of facilities are settled there for fuel storage, disposal of tires and non-hazardous waste, and waste water treatment plants settle there as well. 
Livestock. Within the valley there are areas for cattle grazing mainly for cows and sheep; there are also poultry farms, slaughterhouse facilities and milk processing plants.

Extractive. There is a huge area of materials extraction - gravel, sand and lime - located on the slope of the Cucapah Mountains and Mount Signal and a smaller one on the sandy Mesa of Andrade.

Electricity generation. There are two zones: the combined cycle plants, and the geothermal power generation plants occupying a large area with power plants, sedimentation lagoons, wells and net surface pipes.

Tourism-recreation. Tourism and recreational activities are closely linked to the existing water bodies Rio Hardy, Morelos Dam and canals. Another activity consists of visiting natural areas such as dunes, mountains, volcano and the mountain range, as well as the Biosphere Reserve of the Upper Gulf of California. There are also some other interesting places to visit like some heritage buildings, site museums or places of historical, cultural or technological legacy.

Hunting. In the Mexicali Valley you will find Rancho Los Sanchez, an area of 46 hectares, where hunting of certain bird species is permitted by the authorities: Gambell's Quail (Callipepla gambelli), Mourning Dove (Zenaidura macroura) and Ring-Necked Pheasant (Phaisanus colchicus).

Irrigation infrastructure. A particular feature that defined and structured the valley from its inception was the creation of the wide network of canals and drains. It was because of the availability of water that human settlements were established.

\subsection{Landscape components}

Identification of landscape components was derived from the analysis of photographs, where weights were assigned according to the surface they have in each photo [12]. The valley was characterized by 14 physical and visual units of landscape and therefore 14 photographs were analyzed to measure their landscape components: sky, vegetation, water, rock, soil and pavement. In addition, the presence of each component was examined according to its location in the first, second and third plane.

From this analysis we know that the clear blue sky is an important component as a background that frames figures and it represents about $40 \%$ of the space in the photos. Vegetation such as cultivated fields, trees and shrubs is second in importance with $26 \%$ of coverage, characterized by different colors and textures. Bare soils mainly correspond to land that, due to the type of crops and farming cycles during this surface, accounts for $20 \%$ of the photo coverage. The rocky surface represented by hills, mountain ranges and dunes cover near $7 \%$ of the total area. Water bodies and irrigation channels represent the $7 \%$ shown in the photos. 
Regarding the visual presence of landscape components within the three planes of scenery; it can be said that the second plane accounts for $50 \%$ of the photos, which in most cases fades into the third plane with open views. The latter, being flat and deep, are characterized by the presence of soil, vegetation and water. Landscape components in the first plane are minimal; only 3\% which is represented by lines. The third plane is represented by mountains, hills and dunes, accounting for $7 \%$ of the photos and due to its verticality; they have a strong presence in the scenery. The sky covers the remaining space in the photos.

\subsection{Visual and spatial analysis of the valley}

The Mexicali Valley is bounded on the west by high hills and a mountain range (Centinela, Mayor and Cucapah) which, because of their height, varying from 450 to 750 meters above sea level can barely hold the close space along the road to San Felipe. Although from a different perception level, farther from the valley, the high hills join the verticality of the high mountains that are in a more distant and farther plane, represented by the Juarez y San Pedro Martir mountain range, reaching an altitude of approximately 1400 meters above sea level. Such hills reinforce retention since they are higher than the first ones. There are contained visuals with no significant weight for the distance definition of space, due to the distance of the elements and the presence of fog and dust pollution.

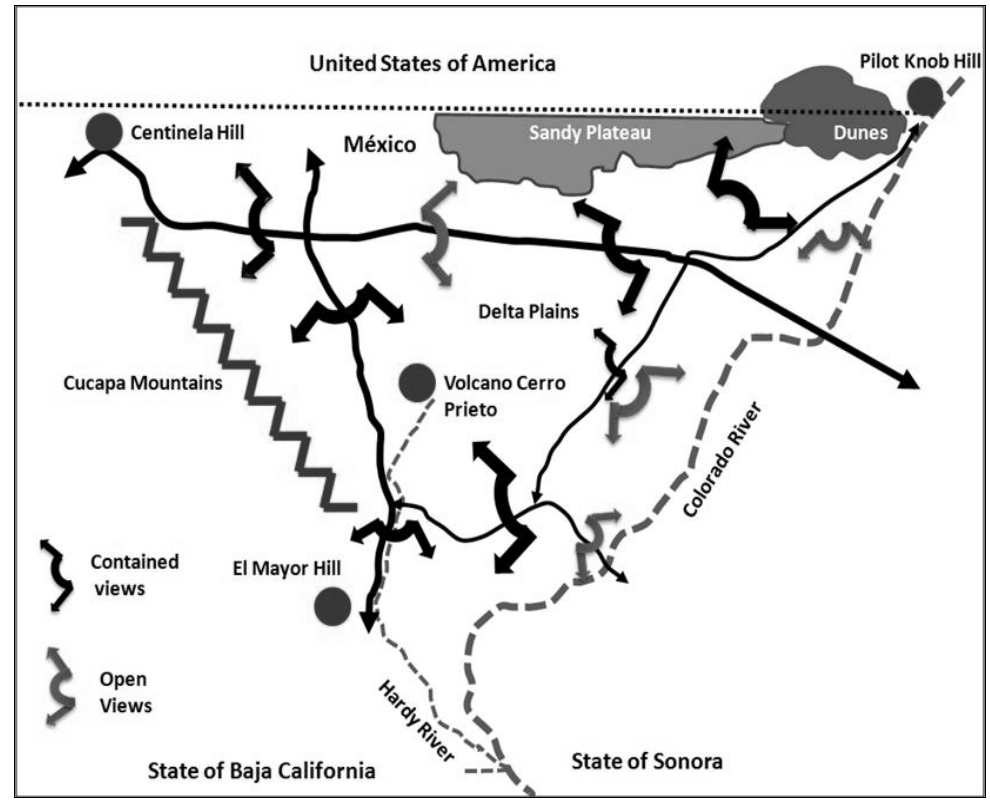

Source: Elaborated by the authors

Figure 3: Views and spatial analysis from the main roads of the Mexicali Valley. 
Mesa de Andrade placed on the north bound of the Mexicali Valley, has around 30 meters height of flat surface, but at a distance, this landform is unnoticeable; therefore it fails to communicate a strong sense of containment. A similar situation occurs with the Dunes and Pilot Knob Hill. Nevertheless, the Mesa, Dunes and Pilot Knob are also landmarks that characterize the north region of the valley and the visual quality is excellent, because it is a mixture of high contrast of colors and textures coming from the desert and agricultural lands.

Another particular feature of the Mexicali Valley is the irregular pattern of land allotment, due to the presence of ancient meandering river and effluents from the old Colorado River, Alamo and Hardy River.

\subsection{Human settlements}

Within the visual analysis of landscape, two main patterns of settlement can be identified: ranches and towns. In the ranch, people have the need to define smaller spaces within the immensity of the plain, according to their own scale by the use of tall vegetation that also meets microclimatic and aesthetic functions. Therefore, there is a pattern of farms surrounded by vegetation that provides scale and containment for living and working spaces. Buildings are usually one level, simple, with sloppy roofs.

Another pattern that can be observed in the valley is human settlements that correspond to urban areas of the ejidos, and colonies. These can be classified into three types according to their urban structure: grid and linear traced irregular polygons described as follows:

Grid trace: they are settlements structured in a grid pattern. There is a main street that concentrates public facilities and services for the population as well as a school, park and church. Properties are large in size, there are single storey homes with gabled roofs, and they have public services such as water and energy and are also surrounded by induced vegetation.

Linear trace: they are squatter settlements over the road right-of-way, canals and railways; there are generally precarious buildings made of adobe and wood or metal sheets, lacking any public services.

\section{Conclusions}

Partial results of this stage of the project highlights the role of the valley as an oasis surrounded by the Sonoran Desert and the Laguna Salada. Thus vegetation, as well as its colors, textures, and the irregular pattern of parcels, provide a distinguishing characteristic compared to the Imperial Valley in California, USA. Cotton and wheat are some of the most important production among the traditional cultivation of this region.

The valley is a huge area and therefore, it is difficult to have a complete image of it; for this reason only partial images can be highlighted, representing 
parts of a wider spectrum of landscape where the means of communication are the main roads and transportation.

The plain highly dominates compared to the vertical elements that are represented by hills, mountains and dunes, which turn the landscape into articulating elements of space that provide identity to the valley area.

Although the presence of water in the landscape is minimal, it is represented by natural water bodies like rivers, ponds, dams and canals. They create a sense of place, because water is linked to the presence of vegetation and birds, breaking the homogeneity of the surrounding landscape.

Finally, another land use that distinguishes this region from the rest is the geothermal power generation in the area of Cerro Prieto.

\section{References}

[1] Marsh, W. \& Dozier, J. Landscape: An Introduction to Physical Geography, John Wiley \& Sons Inc, New York, 1986.

[2] Guide to elaborate the municipal program for ecological land use management (PMOET). National Institute of Ecology, Secretary of Environment and Natural Resources and Secretary of Social Development, 2005. $\quad$ http://sedesol2008.sedesol.gob.mx/archivos/30110901/File/TR PMOETfinal26mayo.pdf

[3] Opdam, P., Foppen R. \& Vos C. Bridging the gap between ecology and spatial planning in landscape ecology. Landscape Ecology 16, pp. 767779, 2002.

[4] Matteuci, S.D. Percepción de la Ecología de Paisajes por investigadores y profesionales argentinos asociados a ASADEP, Revista Fronteras. 8, pp. 17-30, 2009.

[5] Déjean-Pons, M. The European Landscape Convention. Landscape Research, 31(4), pp. 363-384, 2006.

[6] Phillips, A. \& Clarke, R. Our landscape from a wider perspective. The Countryside Planning New approaches to Management and Conservation, ed. K. Bishop \& Phillips, A., pp. 50-67, 2004.

[7] Tress, G., Tress, B., Antrop, G. \& Fry, M. Trends in landscape research and landscape planning. Proceedings of the Frontis Workshop from Landscape Research to Landscape Planning: Aspects of Integration, Education and Application, ed. R.J. Bogers, The Netherlands, pp. 1-10, 2004.

[8] Ahern, J. Theories, methods and strategies for sustainable landscape planning. Proceedings of the Frontis Workshop from Landscape Research to Landscape Planning: Aspects of Integration, Education and Application, ed. R.J. Bogers, The Netherlands, pp. 119-131, 2004.

[9] Swanwick, C. Recent practice and evolution of landscape character assessment. Landscape Character Assessment Guidance for England and Scotland, Scottish Natural Heritage and the Countryside Agency, Topic paper 1, pp. 1-10, 2002. http://www.heritagecouncil.ie/fileadmin/user upload/Planning/LCA_CPD/LCA_CPD_Sep_2011/Reports/LCA_Guidanc e for_England and Scotland.pdf 
468 The Sustainable City VII, Vol. 1

[10] Heritage Victoria. Landscape Assessment Guidelines: For Cultural Heritage Significance 2002, last updated January 2009 with new Assessment Criteria, 2009. http://heritage.vic.gov.au/admin/file/content2 /c7/LANDSCAPEASSESSMENTGUIDELINES.pdf

[11] Stephenson, J. The cultural values model: an integrated approach to values in landscapes, Landscape and Urban Planning, 84, pp. 127-139, 2008. 